\title{
Differences in auditory word recognition thresholds as a function of response hierarchy'
}

\author{
MARTIN F. KAPLAN AND J. BROWN GRIER, DEPARTMENT \\ OF PSYCHOLOGY, NORTHERN ILLINOIS UNIVERSITY, \\ Dekalb, Ill. 60115
}

Recognition thresholds for spoken words were examined as a function of the prior response hierarchy of the Ss. It was hypothesized that Ss with a large number of affiliative adjectives in their hierarchy would recognize affiliative words more readily in a threshold test. The overall hypothesis of an interaction between response hierarchy and word types on threshold was confirmed, but largely because people with few affiliative responses in their hierarchy recognized neutral words more readily than affiliative words relative to those with a large number of affiliative responses.

The existence of individual differences in the perceptual threshold paradigm has long been of interest. A widely accepted explanation of such differences has invoked the presence of differential response hierarchies to ambiguous perceptual stimuli (Goldiamond, 1958; Eriksen, 1963; Pierce, 1963). One problem with this approach is that response hierarchies have rarely been directly assessed, but have instead been inferred by such means as word association reaction time (Goldstein, 1962), personality inventories (Eriksen \& Browne, 1956; Tempone, 1964), and manipulation of a priori probability (Dorfman, 1967). Goldiamond \& Hawkins (1958) provide the notable exception; they developed response hierarchies by varying frequency of repetition of paralogs. A further problem concerns generalization, that is, the vast majority of findings relating response hierarchy to threshold have been within the visual recognition paradigm.

The present study represents an attempt to assess directly response hierarchy and relate it to differential auditory recognition thresholds. Since success has been reported in obtaining relatively valid and stable hierarchies in word association by means of continued association (Garskof \& Houston, 1963: Garskof et al, 1967), it was expected that response hierarchies to perceptual stimuli could be obtained in a like manner. As support for this supposition, Kaplan (1968) found hierarchies arrived at by use of continued association to be predictors of response to social perception stimuli.

Method

Subjects. Introductory Psychology students at Northern Illinois University were given a 7-min period in which to write all the words they could think of that could be used to describe other people. The mean number of responses written was 49.8 with a range of 19-85. Following Kaplan (1968), the hierarchy score was the number of affiliative words occurring in the first 12 responses. Affiliative words were defined as any word appearing on the affiliation subscale of the adjective check list, (Gough \& Heilbrun, 1965 ) and other words agreed upon as affiliative by judges in a previous study (Kaplan, 1968). Two groups of female Ss were selected: a high affiliative response hierarchy $(\mathrm{N}=7)$, having six or more affiliative words in the first 12 , and a low affiliative hierarchy group $(\mathrm{N}=7)$ having no more than one affiliative word in the first 12.

Material. Two sets of nine stimulus words each were chosen: a high affiliative set randomly selected from the list of affiliative words defined above, and a set of "neutral" personal adjectives. The sets were equated for length of word and Thorndike-Lorge word count frequency.

The two sets of words were recorded on individual tape loops with about $7 \mathrm{sec}$ between each repetition. The two sets of tapes were combined and played to each $S$ in a random order.

The equipment consisted of a tape recorder feeding into a Hewlett-Packard model 350-D attenuator and then into one-side earphone of a standard headset.

Procedure. Each tape was started well below threshold and the intensity increased $2 \mathrm{~dB}$ per repetition until two correct identifica- tions in a row were obtained. Starting points for each word were determined on a group of three pilot Ss to give approximately the same number of steps below threshold. The Ss were instructed to guess as soon as they heard any sound through the earphones. The system was neither impedance matched nor calibrated, so that the thresholds are all referenced to attenuation below an arbitrary level.

\section{Results and Discussion}

The average threshold in $\mathrm{dB}$ below an arbitrary reference for each condition is given in Fig. 1. A repeated measures analysis of variance showed three effects significant at or beyond the .01 level: the difference between high and low affiliative words $(\mathrm{F}=$ $35.1, \mathrm{df}=1 / 12)$, the words by personality interaction $(\mathrm{F}=15.3$, $\mathrm{df}=1 / 12)$, and words within categories $(F=6.1, \mathrm{df}=16 / 192)$.

The significant difference between the two sets of words indicates that the neutral words were easier to hear, even though they had been matched for length and frequency with the affiliative list. Possible sources of the difference may lie in the structure of the words, or in the fact that the Thorndike-Lorge tables may not adequately represent their spoken frenquencies (cf. Lazarus, 1954).

The words within categories effect represents the fact that some words were easier to detect than others; this would be expected since the words within a given set were not selected to have the same thresholds.

The thesis of this investigation was that response hierarchy will interact with stimulus type. This prediction is supported by the significant personality by categories interaction. While high affiliative response hierarchy $S$ s had lower thresholds for neutral than for affiliative words, the threshold discrepancy for categories of words was significantly greater for low affiliative response hierarchy Ss. In other words, the threshold for affiliative relative to neutral words was considerably higher in the low affiliative hierarchy group. It should be expected that the high affiliative hierarchy group would have a lower threshold for affiliative relative to neutral words; that this was not the case may possibly be attributed to two factors: as previously mentioned, the neutral words may have been structurally easier to recognize, and the high hierarchy group, while possessing more affiliative response

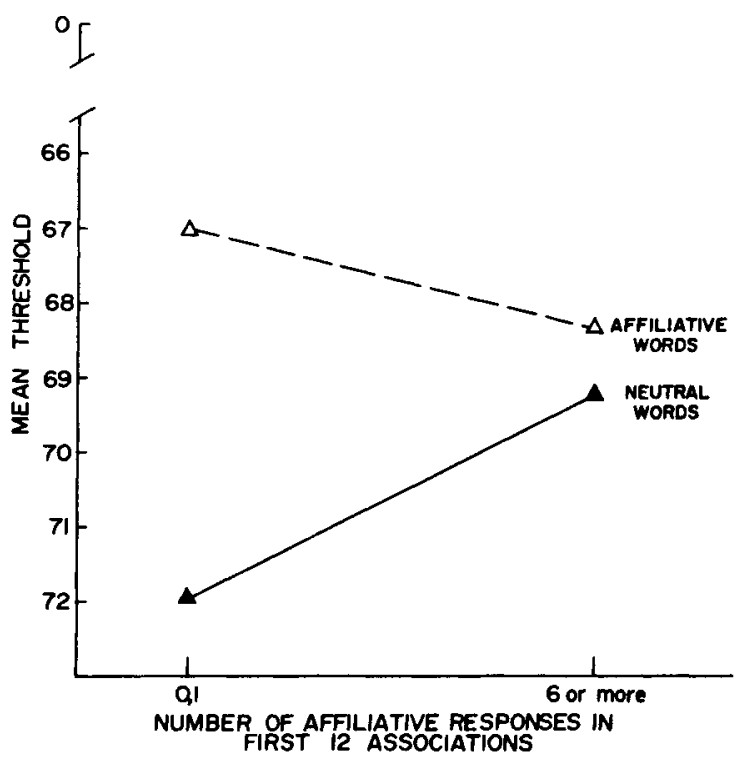

Fig. 1. Thresholds for affiliative and neutral words as a function of response hierarchy. 
tendencies than the low group, may not themselves possess more affiliative relative to neutral responses. Figure 1 shows that the high hierarchy group differs relatively from the low group but still maintains higher thresholds for affiliative words. Therefore, it may be concluded that group differences in threshold are a function of differences in response hierarchies, and that relative thresholds for different stimulus classes are a function of relative dominance of response tendencies toward these classes.

\section{REFERENCES}

DORFMAN, D. D. Recognition of taboo words as a function of a priori probability.J. Pers. soc. Psychol, 1967, 7, 1-10.

ERIKSEN, C. W. Perception and personality. In J. M. Wepman and R. W. Heine (Eds.), Concepts of personality. Chicago: Aldine, 1963.

ERIKSEN, C. W., \& BROWNE, C. T. An experimental and theoretical analysis of perceptual defense. J. abnorm. soc. Psychol., 1956, 52, 224-230.

GARSKOF, B. E., \& HOUSTON, J. P. Measurement of verbal relatedness: an idiographic approach. Psychol. Rev., 1963, 70, 277-288.

GARSKOF, B. E., SHAPIRO, E. B., \& BRANDSTADTER, J. Order of emission in continued association as a predictor of individual free recall. Psychon. Sci, 1967, 7, 209-210.

GOLDIAMOND, I. Indicators of perception: I. Subliminal perception, subception, unconscious perception: an analysis in terms of psychophysical indicator methodology. Psychol. Bull., 1958, 55, 373-411.

GOLDIAMOND, I., \& HAWKINS, W. F. Vexierversuch: the log relationship between word frequency and recognition obtained in the absence of stimulus words. J. exp. Psychol., 1958, 56, 457-463.

GOLDSTEIN, M. J. A test of the response probability theory of perceptual defense. J. abnorm. soc. Psychol, 1962, 63, 23-28.

GOUGH, H. G., \& HEILBRUN, A. G., Jr. Joint manual for the adjective check list and the need scales for the ACL. Palo Alto: Consulting Psycholgists Press, 1965.

KAPLAN, M. F. Behavior prediction responses as a function of judge's response hierarchy. Paper presented at Midwestern Psychological Association, May, 1968.

LAZARUS, R. S. Is there a mechanism of perceptual defense?A reply to Postman, Bronson, \& Gropper. J. abnorm. soc. Psychol., 1954, 49, 396-398.

PIERCE, JAN Determinants of threshold for form. Psychol. Bull., 1963, 60, $391-407$.

TEMPONE, V. J. Extension of the repression-sensitization hypothesis to success and failure experiences. Psychol. Rep., 1964, 15, 39-45.

\section{NOTE}

1. This investigation was supported, in part, by a grant from the Northern Illinois University Deans Fund, awarded to the first author. 